\title{
Research and Improvement of the Teaching Method of Analog Electronic Technology
}

\author{
Youhui Zou ${ }^{1}$ Renbo $\mathrm{Xu}^{1,2, *}$ and Yanping $\mathrm{Wei}^{1}$ \\ ${ }^{1}$ School of electrical and information Engineering, Nanchang Institute of Science and Technology \\ Nanchang, 330108, china. \\ ${ }^{2}$ Physics and Microelectronics Institute, Central South University Changsha, 410083, china.
}

Keywords: Analog Electronic Technology; Teaching Methods; Experience; Research and Improvement.

\begin{abstract}
Previously, many students reflected that the analog electronic technology is more difficult to learn. In this paper, the problems encountered in the teaching process are analyzed and studied, such as circuit theory analysis and system simulation, summed up a number of teaching methods and means (such as circuit analysis and simulation techniques, etc.) from teaching materials to teaching methods and auxiliary experiments.

Analog Electronic Technology is the basic course of electronic technology. It is the key course for students to form and train the basic qualities of electronic circuit awareness and understanding. It is possible to design an application circuit that satisfies the technical requirements, reliable performance and low cost, and even forms an electronic system of perfect function through mastering the basic principles, basic characteristics and basic knowledge of interconnect matching between circuits of the basic electronic circuit. This paper analyzes and guides from the following aspects.
\end{abstract}

\section{Definite learning purpose}

First of all, teachers should let students know the role of learning "analog electronic technology" class. Many students begin to learn electronic analog in order to participate in electronic design competition or when they have problems with other specialized courses, this is not only a waste of time, and then study the effect is not ideal. If the teacher tells the students that the course needs modular electrical knowledge according to the requirements of each department, emphasizing the importance of this course, Students will pay attention to which model knowledge is needed as a basis when they start to learn other professional course in the future.

\section{The key to understand the circuit diagram}

Students should master the most basic circuit diagrams in each chapter, such as amplifying circuits, coupling circuits, feedback circuits, oscillating circuits, switching circuits, etc. Many analog electronic circuits make enlarge the circuit as the core, the early use of discrete components, such as transistors, field effect transistor of the amplifier circuit, now more amplifier circuits are constructed. It requires students to have a clear understanding of the operational amplifier circuit. Many circuit diagrams are composed of these basic circuits, students can firstly understand the role of the overall circuit, the device function, signal direction and so on, the large circuit can be divided into several pieces according to different functions, analyzing the role of each part, then students will effectively link the knowledge of multiple units and improve the ability to analyze and judge the circuit. As shown in Figure 1, the utility model is an application circuit based on a lt3846 double output boost type LED driver which drives two strings of $200 \mathrm{~mA}$ with a constant current of LED. The power supplies the SW1 and SW2 pins of the chip lt3846 via the L1, L2, D1, D2 ovp1 and ovp2 pin voltage respectively, related clock signal connected to the chip CTRL1 and CTRL2 feet, 
the PWMI and PWM2 pins are connected to the switch tubes V1 and V2 respectively to control the pulse width, the two series parallel load led are respectively driven by V1 and V2 drain electrodes, R2, C5, R4 and C6 are connected in series and ground to improve the system performance and stability.

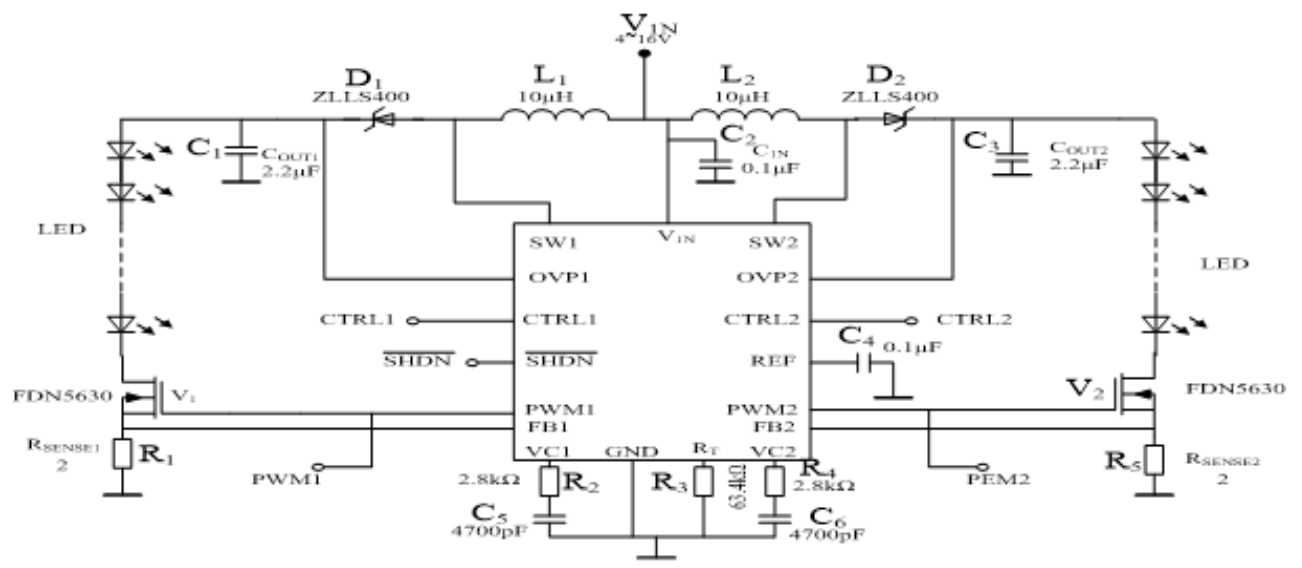

Fig.1 An application circuit based on a lt3846 double output boost type LED driver

\section{Learn how to use simulation software}

Now many school modeling courses are combined with electronic craft training courses. Teachers can spend some time to guide students to learn Multisim, Proteus and other simulation software, select some simulation topics, operations and demonstrations for students to see. Teachers can guide students to practice the basic circuit of textbooks in the beginning, then ask students to do simulation exercises on the experiments to be done after mastering these simulation software, the simulation testing data is compared with the measured circuit data, and the reasons for the data error are analyzed. As shown in Figure 2 and 3, control system voltage and current tracking (power factor) are showed very clearly, the effect is intuitive, students are easy to accept. The students can use the software to simulate in the production of the actual circuit in the course of electronic technology training; The students can get the ideal experimental data though the continuous debugging of the components of the circuit parameters, and then improve the circuit board to improve the installation and production to avoid duplication of the production of circuit boards and the purchase of components, converting a virtual abstract circuit into a visible circuit.

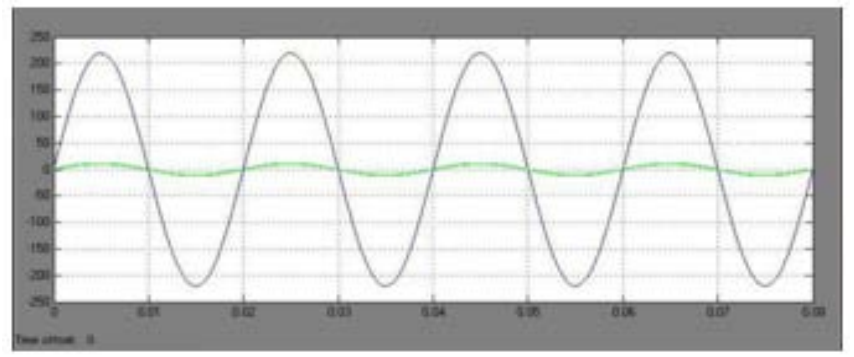

Fig.2 Waveform figure of AC input voltage and current

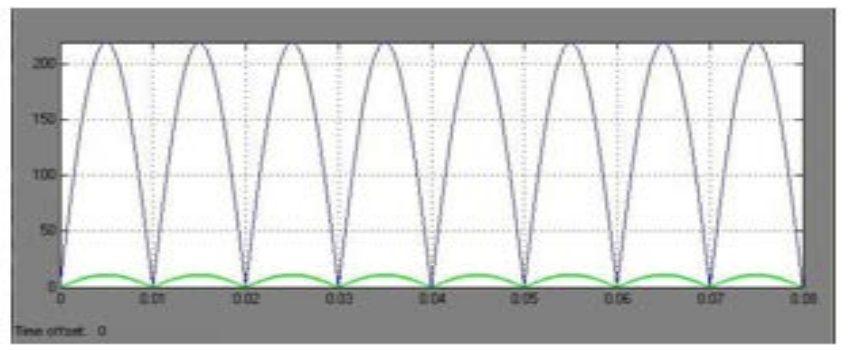

Fig.3 Input voltage and current Waveform figure after rectifying 


\section{Multimedia teaching}

It is necessary to elaborate multimedia courseware according to the contents of the teaching materials. The traditional teaching method is more abstract and boring which is difficult to imagine. Teachers should add some content according to their own understanding to help students to learn, avoiding simple and straightforward statements. Such as P-type semiconductors and N-type semiconductor internal structure, how do the electrons and holes in the two kinds of semiconductor move? How does it move when the voltage is biased and skewed? If teachers design and manufacture animation forms of multimedia courseware for demonstration, students will be able to directly understand the characteristics of the PN section and lay a good foundation for the following chapter to understand the work principle of the transistor. The results of simulation software through multimedia presentation to the students will play a visual effect, and arouse students' interest in learning.

\section{Pay attention to experimental teaching}

The experiment can help the students to strengthen the knowledge of mode electricity and train the most basic skills and experimental ability of the analog electronic circuit experiment. For example, the students can find out the specific cause of the experimental data when fault occurs in the circuit or there is a greater deviation in the measurement value through the circuit diagram to find out the problem. The traditional verification experiment can only consolidate the corresponding knowledge points, you should also increase the design and comprehensive experimental content if you want to further stimulate students 'interest in learning and improve students' practical ability. This will strengthen the students on the theoretical knowledge of the flexible application and strengthen the practice according to some knowledge to achieve the purpose of learning.

In a word, the simulation of electronic teaching should enable students to have a clear learning purpose, strengthen the interaction with students, and master the difficulties and interests that students encounter in their studies, so that students can actively participate in the learning process through the simulation software of learning as a complement to teaching. Practice has proved that these teaching methods can improve the teaching efficiency of the classroom, enrich the teaching content, improve students 'interest in learning, and cultivate students' innovative ability and practical ability.

\section{Acknowledgments}

This research was financially supported by Key scientific research projects of Jiangxi Provincial Department of Education (Grant NO.GJJ161229、GJJ161218). Nanchang institute of technology research start-up funding.

\section{References}

[1] Jing Hong. Exploration on Teaching Reform Mode of Analog Electronic Technology [J]. Journal of Electrical \& Electronic Education, 2011, 30 (3):4-5.

[2] Wang Ziting, Wu Rong and other people. EDA technology and application [M]. Lanzhou: Lanzhou University Press .2013.

[3] Zhao Hong. Research Teaching and the Reform of University Teaching Method[J]. Higher Education Research, 2013, 27 (2): 71-75.

[4] Y. Hu, M. M. Jovanovic. LED Driver with Self-Adaptive Drive Voltage. IEEE Transactions on Power Electronics, 2012, 23(6): 116-125

[5] Xiong Wei, Hou missionary and other people. Circuit design of Multisim 7and simulation application on Multisim 7 [M]. Beijing: Tsinghua University Press .2010. 
[6] Y. K. Cheng, K. W. E. Cheng. General Study for Using LED to replace Traditional Lighting Devices. 2nd International Conference on Power Electronics Systems and Applications, Hong Kong, 2012.25(9):173-177

[7] Liu Baocun. Problem - based Learning Model in American Research Universities[J]. China Higher Education Research, 2014 (10): 60-62.

[8] Zhang Yantong. British Higher Education "Ability Education Declaration" and "Action Based Learning"[J]. Comparative Education Research, 2012 (1): 11-16.

[9] H. van der Broeck, G. Sauerlander, M. Wendt. Power Driver Topologies and Control Schemes for LEDs. IEEE Applied Power Electronics Conference, Anaheim, 2011,31(5):319-325

[10]Zhu Qingshi. Taking value of innovative quality and cultivating successful innovative talents [J]. China Higher Education. 2012 (1): 81-84.

[11] Zhang Zengliang, Jiao Zhi. Several Typical Methods in "Analog Circuits" Teaching[J]. Journal of North China Institute of Aerospace Technology, 2012 (4) :20-22. 